\title{
Study on the University Students' Self-expressive Tendency in Mongolia
}

\author{
Davaa Jagdag $^{1} \&$ Zoljargal Dembereldorj ${ }^{2}$ \\ ${ }^{1}$ Department of Pedagogy and Psychology, Division of Social Sciences, School of Sciences, National University of \\ Mongolia, Mongolia \\ ${ }^{2}$ Center of Foreign Languages, Division of Humanities, School of Sciences, National University of Mongolia, \\ Mongolia \\ Correspondence: Zoljargal Dembereldorj, School of Sciences, Division of Humanities, Center of Foreign Languages, \\ National University of Mongolia, Mongolia. E-mail: zoljargald@num.edu.mn
}

Received: December 7, 2016

Accepted: December 27, $2016 \quad$ Online Published: December 30, 2016

doi:10.5430/ijhe.v6n1p163

URL: http://dx.doi.org/10.5430/ijhe.v6n1p163

\begin{abstract}
The study aimed to explore Mongolian students' tendency of self-expression and a conduct of self-study at one university of Mongolia. It employed quantitative research method to explore the relationship between self-expression and self-study and examined them in terms of age, gender, years of study and field of study. The chi-squared test found that there is a significant relationship between self-expression and the ability to conduct self-study. We concluded that students who conduct self-study or has an ability of self-study tend to self-express in the context of Mongolian education. Significant relationships between age, year of the class and self-expression implies that self-expression develops as the student becomes matured and confident with an increase of their educational level.
\end{abstract}

Keywords: Self-expression, Self-study, Mongolian, Higher education, University student

\section{Introduction}

In the years of rapid socio-economic and culture-intellectual development of Mongolia, it is crucial for a professional with higher degree to express his or herself properly, conduct an independent self-study and live independently from others. It is, in one hand, social demand, but, on the other hand, an issue of implementation of an educational purpose of the country. Since 2012, the country has been reforming educational contents and methodology to help students to learn abilities and skills. However, this issue has been criticized to have not yet well resolved. For instance, an ability to self-express is one of the major characteristics of becoming an individual. It is crucial at the societal and individual level. However, it is commonly viewed that

"It is limited for the university students to express their opinion and discuss openly at our university. Our system is different from the western system where the class hour is spent mostly through discussions and talks of the students than the instructor him or herself. The ends of learning and teaching has become separated; and the instructors are authoritative enough that students graduate without an ability of self-expression" (Jargalsaikhan, 2015, p. 8).

In addition, Enkhtaivan (2013) observed that young officers with good theoretical knowledge lack the ability of self-expression. Because they are not able to express themselves properly to their colleagues, they become depressed at work. In sum, he concluded that Mongolian young officers should gain the ability of self-expression while they are university students (Enkhtaivan, 2013, p.6).

\section{Literature Review}

There is a good number of studies that discuss individual self-expression. Bogush (2008), Kononko (1983), Chanilova and Shkeli (2002) studied individual self-expression and individuality. For instance, Bogush (2008) viewed that self-expression is a special ability which children reveal their ego and express themselves through fairy-tales (p.203). Moreover, there are many studies on creative self-expression such as Brikunova (2005), Gudkov (2006), Djafarova (2016), Zykova (2008), Mezal (2010), Onishuk (2012), Soldatova (2000), Kharchenko (2003). Self-expression was also studied as an individual emotional self-expression (Shindyaeva, 2004) and self-expression through talks (Anishuk, 2008, Bogush, 2008, Shkuratova, 2007). Particularly, Anishuk (2008) viewed that self-expression is an ability to 
evaluate his or her personal opinion, feelings, willingness, and attitudes towards others, and to express individual peculiarity and creative activities (p.158). Moreover, Anishuk (2008) divided self-expression into cognitive aspect (ethics and knowledge of expressing one's self verbally, and becoming aware of wrong self-expression), emotional and evaluative aspect (models of proper verbal expression) and behavioral aspect (an ability to communicate with others in a socially acceptable manner) (p.14).

Brikunova (2005), Krinitsyna (2009), Mezal (2010), Michaelova (2009), Salyutnova (2012), Stali (2005), Yafaliyan (2009) researched self-expression through arts; Dengina (2000), Onishuk (2012) and Kharchenko (2003) studied issues of self-expression while learning music; Belyakova (2007) researched on self-expression issues during the class. For instance, Belyakova (2007) studied self-expression through music, dancing and verbal means by observing listening to music, singing, rhythmic movement and performing improvisation during the class (p.24). Besides, Omelichenko (2012) studied self-expression through scientific research. These studies expanded the context and ideas of self-expression extensively.

Zykova (2008) contended that self-expression is an ability to promote his or her willingness and show individual peculiarity through creative works. Specifically, a person should emphasize creative possibilities to express his or her willingness in which creative self-expression is a relation among aspects of content cognition, emotional motivation, communicative function and reflexive- evaluation (Zykova, 2008, p.7). An ability of self-expression is characterized with autonomy, attitude, esthetical approach to surrounding environment, emotion, imagination, intuition, encouragement (Mezal, 2010, p. 55).

Djafarova (2016) documented that there are studies on self-expression of youngsters, many of which viewed self-expression in terms of the activities (p.37). "A self-expressive ability is developed through communication and activities. It implies that a person develops by communicating with others and conducting activities." (Davaa, 2014, p.82). Thus, self-expression can be related with students' activities to conduct a self-study such as assignments and independent projects.

The issue of student's self-expression has been noted well on legal documents of education in Mongolia. For instance, on the education law on Mongolia, it is emphasized that instructor "should approach to the student's individual worldview and opinions with respect" (Ministry of Education, Science and Culture, 2016). Little has been studied on self-expression in Mongolia from the psychological and pedagogical aspects from 2000 through 2016.

Self-expression tends to be viewed as a speech skill in Mongolia. However, communication with other's in a proper manner is an essential skill and personal development of human life. That is, it is not a secret that a person succeeds in utilizing his or her ability, experience and opportunities when he so she has a skill to express his or her self well (Baatarsuren, 2015).

There are some other arguments on self-expression. For instance, it is physiologically healthy to express his or herself properly and learn to be able to communicate skillfully (Baatarsuren, 2015). It is considered as an ability of self-organization within the framework of societal skill for self-expression. Societal skill is a complexity of positive traits, proper habit, positive ethical norms and "humane" personality to communicate with people who we encounter every day while working, studying and living together. When viewed as an ability, self-expression is an object of an educative process characterized by its lead-ability that an individual can learn, obtain and develop (Dorj, 2012).

In recent years, employers are more interested in recruiting a person who is creative and able to self-express. One employer mentioned, "I am eager to recruit free spirited artists. They think open and faster to learn new things efficiently. In addition, they have the ability to express themselves well. It is a crucial trait for the workers in the field of investment" (Achit-Erdene, 2016, p. 4). With regard to the urgency of learning self-expression in the context of Mongolia, the purpose of the study is to explore self-expression of university students of Mongolia. We hypothesize that the more student has an ability to self-express, the better he or she conducts a self-study. To achieve our purpose, we reviewed literature on students' self-expressive tendency and ability and their self-study, and attempted to determine relationship between students' self-expressive tendency and their conduct of self-study.

Scholars defined self-expression from different perspectives. Here, we explored students' self-expression within the framework of student's verbal self-expression, initiation, presentation, systematic thinking, developing projects, communication, modeling, and completing creative tasks. An ability of self-expression is developed within the framework of communication and action. Djafarova (2016) emphasized that many studies on youngsters' self-expression have been researched from the aspect of action. Hence, this study focuses more on students' engagement in learning and their ability to conduct self-study. 
More specifically, the study concerns the aspects of students' verbal self-expression, individual self-expression, creative self-expression, self-expression of personal emotions and self-expression in terms of scientific researching. These abilities are interrelated with students' ability to conduct a self-study. "Having an ability to be independent means the person can organize his or her actions, implement them individually, make an evaluation and determine further purposes without anyone's pressure, requirements and surveillance" (Gombo, 2013, p. 74).

Although pedagogical purposes, objectives, content, teaching methods and evaluations are crucial for students' ability to conduct self-study, their motivation, willingness, efforts and an ability to self-express is equally important as well. One of the factors that students develop self-expressive ability is a way that students complete assignments and defend them. They take many forms "to foster students 'independent assignments such as reading and taking notes from original texts, writing a report, conducting experiments and research, solving problems, and conducting professional practicum" (Davaa et. al, 2013, p. 75).

\section{Method}

The study surveyed 900 undergraduate students in one of the prestigious universities which is located in Ulaanbaatar, Mongolia. The survey was conducted during the spring semester of 2016. We employed 888 surveys which was deemed to be complete out of 900 surveys. The survey consisted of demographic information including choices of the university, gender, age, field of study, and questionnaires to explore students' self-expression and self-study ability. Cronbach alpha of the self-expression and self-study ability was .649. The questionnaire consisted of five major questions assessing student's perception of their ability to apply their skills; their satisfaction for their own learning skills; their perception of the level of the skills; and the application of self-study skills. These major questions consisted of 8 to 10 sub-questions with Likert scale ranging from categories always to none; and regularly to none. The subscale alpha score of the self-study was .630, whereas self-expression was .849 . The questions were developed through previous studies related on self-expression and self-study ability. Further, we employed chi-squired test to look if there is a relationship between self-expression and self-study and other demographic variables.

\section{Results}

The study explored perception of Mongolian students' ability to conduct self-study and their self-expressive capacity at one prestigious higher education institution in Mongolia. As the variables are categorical, we employed chi-squared test to explore if there is a significant difference between students who perceive to conduct self-study and those who perceive to self-express. Moreover, we tested if there is an association of self-study ability of Mongolian students and their expressive attitude. We also analyzed self-expressive attitude and tendency to conduct self-study with the categorical variables such as age group, year of classes and gender.

First, we began by examining the difference between self-expressive attitude and tendency of self-study. As the test revealed, 30.1 percent of students perceive to conduct self-study sometimes and similarly have the tendency to self-express sometimes. Moreover, 22.7 percent or 202 students is the second largest pool of students who perceive to be conducting self-study and have higher tendency to self-express most of the time. Students who also perceive to conduct self-study frequently have also high self-expressive attitude counted at 113 or 12.7 percent of total population. The results of perceptions of self-study and self-expression among students show significant relationship between two variables $\left(x^{2}=277.031, d f=12, p=.000\right)$.

Next, we examined the association of self-study and self-expressive attitude according to gender of the students with chi-squared test as well. We found that there is no significant association between gender and self-expressive attitude among the students. In addition, there is no significant relationship between gender and the perception of self-study ability. This shows that perception of self-expressive attitude and self-study ability is independent from students' gender.

Followed by the gender test, we looked at the relationship between age group with self-expressive attitude and self-study ability of the students. The result shows that there is a significant relationship between age group of the students and self-expressive attitude $\left(\mathrm{x}^{2}=51.908, \mathrm{df}=12, \mathrm{p}=.000\right)$. Students aged 19-20 perceive to have self-expressive attitude sometimes (188 or 21.2 percent of total population) and most of the time (159 or 17.9 percent of total population) as compared to other age groups. Students aged 18 (113 or 12.7 percent of the total population) perceive to be self-expressive sometimes than the age group of 19-20 years. Students aged 21-24 (100 or 11.3 percent of the total population), on the other hand, perceive to self-express most of the time. The above shows that students aged 19-20 tend to self-express more than any other age groups. Interestingly, 18 years olders tend to self-express sometimes, whereas 21-24 years olders tend to do so most of the time. As for the relationship between 
age groups and self-study ability, there are more students aged 19-20 who perceive to conduct self-study sometimes ( 245 or 27.6 percent of total population) and regularly (119 or 13.4 percent of the students). Students aged 18 perceive to self-study sometimes (144 or 16.2 percent of total population), whereas students aged 21-24 perceive similarly self-study sometimes constituting 56.5 percent of students in the same age group. We also found that there is a significant relationship between age groups and the perception of self-study ability $\left(x^{2}=38.826, d f=9, p=.000\right)$.

After looking at the age group of the students' perception of self-expression and self-study ability, we examined differences between self-expressive attitude and self-study ability according to their years of classes at their respective university. Most of the students of each class year ranging from freshman year to senior year answered to self-express sometimes: 113 freshman, 122 sophomore, 105 junior students. Most junior students (109 or 12.3 percent of total population) tend to self-express "most of the time" as compared to other class groups. Moreover, 95 or 10.7 percent sophomore students answered to self-express most of the time. This shows that sophomore students have more tendency to self-express sometimes, while junior students do so most of the time. The result shows that there is a significant relationship between level of study of class year and self-expressive attitude of the students $\left(x^{2}=61.235, d f=12, p=.000\right)$. When we examined the difference of self-study ability and class year, we, however, found not significant relationship between the perception of self-study ability and class year of the students $\left(x^{2}=20.115, d f=9, p=0.17\right)$.

As for the final examination, we tested to see the relationship between major of students, and their perception of self-expression and self-study ability. The result shows that there is no significant relationship between the tendency of self- expression and student's relevant major $\left(\mathrm{x}^{2}=12.257, \mathrm{df}=8, \mathrm{p}=.140\right)$. On the contrary, there is a significant relationship between major and students' perception of self-study ability $\left(x^{2}=30.773, d f=6, p=.000\right)$. Students in humanities answered the most to conduct self-study sometimes totaling 203 or 22.9 percent of the total population. However, students in the field of social sciences answered the most to self-study "regularly" (109 or 47.6 percent of within the category of perception of self-study ability).

\section{Conclusion}

We explored students' self-expression and their ability to conduct self-study and examined their relationship according to age, gender, level of class and their majoring field. The result suggests that self-expression and self-study ability are equally important for students' development in Mongolia. However, gender does not owe any association with student's perception of self-expression and the ability of self-study. It can be explained from Mongolia's sociocultural aspect that women are treated with greater equality in terms of educational opportunities and social status as men in Mongolia. With this regards self-expression and self-study do not differ between man and women. Another test of association of self-study and self-expression with different age groups suggests that age may play an important for both self-study and self-expressive attitude of the students. Students aged 21-24 years specifically perceive to have higher self-expressive attitude and self-study as compared to other age group. This suggests that this age group is the age that students in Mongolia ideally feel confident to self-express and therefore higher ability to self- study. It can also be viewed that this period of time is crucial for student's further socio-academic development when curriculum and teaching is purported to foster self-expression and self-study attitude of students.

One of the interesting results was the significant association between self-expression and year of the students' class and no significant association between self-study ability and year of the students' class as both self-expression and self- study ability is associated significantly. It can be explained that self-study is taken for granted for students as their doing is studying while self-expression varies according to the levels of the study. It may be also related to the fact that student's self-expression is more prominent especially in the second and third year of their study at the university. They may feel more confident and "experienced" to be a university student. Moreover, curriculum and classes provided at the second and third year may have some effect on students' perception of self-expression as they may be studying subjects that demand more self-expression. We can conclude that students' self-expression and student's ability of self-study is different conception when considered in relation with students' year of the class.

On the contrary, we found significant relationship between students' self-study ability and their field of study, and no significant relationship between self-expression and the field of study. The result suggests that students in the field of humanities and social sciences are active in conducting self-study as compared to the students in the field of natural science. If we concern the perfect association of self-expression and self-study with this result, there can be an explanation for small number of students of the natural sciences who perceive to self-express. The reason is that students in the field of natural sciences are urged to or required to self-express as students in the humanities or social sciences. 
Drawing from this study, we can conclude that students who conduct self-study or has an ability of self-study tend to self-express in the context of Mongolian education. Significant relationships between age, year of the class and self-expression imply that self-expression develops as the student becomes matured and confident by increasing the level of their study.

\section{References}

Achit-Erdene, D. (2016). "The Door to become an elite". http://mongolianeconomy.mn/mobile

Anishuk, A. M. (2008). Optimization of self-expressive process of pre-school children and its environment. Dissertation. Nijn.

Baatarsuren, S. (2015). Young people should create not to be liked by others but for themselves. http://khongornutag.mn

Belyakova, Ye.V. (2007). Anthropological approach as a condition of self-expression of pre-school children solving a complex problems. Yekaterinburg.

Bogush, A. M. (2008). Creative self-expression of pre-school children in artistic and musical activities. Odesa: Cherkasov.

Brikunova, S. S. (2005). Pedagogical environment of children's development of creative sefl-expression in an elementary school district. Dissertation. Rostov-na-Donu.

Chanilova, N. G. \& Shkeli, V. (2002). Individual self-expression as a way of student integration in a social settings. http://edc.saratov.ru

Davaa, J. (2014). Pedagogy. Soyombo printing. Ulaanbaatar.

Davaa, J., Narantuya, M., Sarantuya, G., Tuya, B., Tsogzoolmaa, D., Erdenechimeg, Sh. (2013). Educational technology of higher education. Artsoft. Ulaanbaatar.

Dengina, I. O. (2000). Study on speaking in a foreign language of the high-school students in gymnasium from the project approach. Dissertation. St.Peterburg.

Djafarova, O. (2016). Fostering creative self-expression of elementary students through music activities. issertation. Kiev.

Dorj, S. (2012). Social skills for students to acquire. www.khu.edu.mn

Enkhtaivan, S. (2013). Skills of self-expression. http://www.soyombo.mod.gov.mn/.

Gombo, D. (2013). Choosing your profession. Soyombo. Ulaanbaatar.

Gudkov, I. B. (2006). Future actor's creative self-expression during the self-study activities. Dissertation. Krasnoyarks.

Jargalsaikhan, D. (2015). Status of higher education institutions. www.jargaldefacto.com/article/deed

Kharchenko, I. I. (2003). Self-determination of youngsters in a changing society: choice of life strategies, principles and pursuit. Dissertation. Novosibirsk.

Kononko, Ye. L. (1983). I myself. Radyanska schola.

Krinitsyna, A. V. (2009). Self-expression of elementary school students through arts as self-awareness and world around them. Pedagogy of arts, (4), 153-161.

Mezal, A.R. A.(2010). Formation of creative self-expression of the students during the artistic courses at the pedagogical institution. Voronej.

Michaelova, O. S. (2009). Self-realization of students of 5-7 grades at a drawing class in a collective arts activities. Dissertation. St. Peterburg.

Ministry of Education, Science and Culture, (2016). www.meds.gov.mn/EduLAW. From www.meds.gov.mn

Omelichenko, Ye. A. (2012). Building culture of self-expression among bachelor's students of pedagogical institute. Proceedings from the $4^{\text {th }}$ International Conference on contemporary theoretical-methodological issues. Novosibirsk.

Onihsuk, I. A. (2012). Development of self-expression among pre-schoolers in music activities. Dissertation. Kiev. 
Salyutnova, V. I. (2012). Pedagogical activities for creative self-expression of pre-school students in drawing activities. Dissertation. Chita.

Shindyaeva, Ye. A. (2004). Building culture of emotional self-expression of teenagers of secondary school. Dissertation. Magnitogorsk.

Shkuratova, I. P. (2007). Psychology of individual differences. Moscow.

Soldatova, A. A. (2000). Creative self-expression as a way pedagogical .means for preparing future teachers in an innovative activities. Dissertation. Irkutsk.

Stali, M. G. (2005). Developing abilities of self-expression in a drawing class. Arts of drawing in schools, (3), 65-69.

Yafaliyan, A. F. (2009). Arts influence on spiritual health of children in a drawing class. Pedagogical education, (1), 130-142.

Zykova, Ye. M. (2008). Orientation of the students at the pedagogical college for self-expression. Dissertation.Krasnoyarks. 